January 2005

\title{
Drug related critical incidents
}

F A. Khan

Aga Khan University, fauzia.khan@aku.edu

M Q. Hoda

Aga Khan University, qamar.hoda@aku.edu

Follow this and additional works at: https://ecommons.aku.edu/pakistan_fhs_mc_anaesth

Part of the Anesthesia and Analgesia Commons, and the Anesthesiology Commons

\section{Recommended Citation}

Khan, F. A., Hoda, M. Q. (2005). Drug related critical incidents. Anaesthesia, 60(1), 48-52.

Available at: https://ecommons.aku.edu/pakistan_fhs_mc_anaesth/212 


\title{
Drug related critical incidents
}

\author{
F. A. Khan ${ }^{1}$ and M. Q. Hoda ${ }^{2}$ \\ 1 Professor, 2 Associate Professor, Department of Anaesthesia, Aga Khan University, Stadium Road, P.O. Box 3500, \\ Karachi 74800, Pakistan
}

\begin{abstract}
Summary
Drug related incidents are a common form of reported medical errors. This paper reviews the critical incidents related to drug errors reported from the main operating theatre suite in a teaching hospital in a developing country from January 1997 to December 2002. Each report was evaluated individually by two reviewers using a structured process. During this period, 44874 anaesthetics were administered; 768 critical incidents were reported, 165 (21\%) of which were related to drug errors. Underdosage, side-effect/drug reaction and syringe swap were the most common. A total of $76 \%$ were classified as preventable; $56 \%$ due to human error and $19 \%$ due to system error. High risk incidents accounted for $10 \%$ of all drug errors and most of these were related to the use of neuromuscular blocking drugs. This analysis has been found useful in addressing some issues about priorities.
\end{abstract}

Correspondence to: Fauzia Anis Khan

E-mail:fauzia.khan@aku.edu

Accepted: 20 September 2004

Incident reporting is one of the techniques used in quality assurance programmes for improving patient outcome. Critical incident analysis was introduced to anaesthesia practice by Cooper et al. [1] in 1978 and is now firmly established. This analysis can be used for auditing work practice, for correction of factors contributing to the incident and for identification of recurrent problems [2]. To date, the largest published series has been reported by the Australian Incident Monitoring Study (AIMS) [3]. In an analysis of the first 2000 incident reports of AIMS, one of the common categories of incidents reported was drug errors, which formed $32 \%$ of the incidents [4]. There is a need to study these adverse drug events further and to identify the types of error and types of adverse outcomes related to preventable events. A study from the USA looked at 10 published papers related to preventable drug events and reported a median [range] preventability rate for adverse drug errors in hospitals of 35\% [19-73\%].

The aim of our review was to assess the incidence of adverse and potential adverse events related to drugs used in anaesthesia in a university hospital in a developing country and to analyse avoidable events in order to develop prevention strategies.

\section{Methods}

The Institutional Ethical Committee did not require approval of the project, which was carried out according to local guidelines. Our hospital is a 500-bed urban, university-affiliated hospital with an approximate current annual workload of 9000 surgical patients (annual number of anaesthetics given 7883-8882). It has a main operating theatre suite with 10 operating theatres covering all anaesthetic subspecialties including cardiac, neurosurgery and paediatrics, two daycare and one obstetric operating theatre.

The anaesthesia providers are 21 full time and three part time consultants, 10 senior registrars and 36 residents in a structured 5-year residency programme. Assistance in the operating theatre is provided by anaesthetic technicians. Anaesthetic drugs are drawn by the anaesthesia residents for each patient before induction of anaesthesia. A specified floor stock of all anaesthetic drugs is kept in a storage area in the operating theatre suite. A drug trolley of commonly used anaesthetic drugs is also available in each operating theatre.

The critical incident monitoring programme was introduced in the main operating theatre suite in 1996 on an anonymous and voluntary basis. Critical incident forms are available in every operating theatre and are 'posted' in a locked box kept in the recovery room area, from which they are collected by the Critical Incident Coordinator every month. These forms are then presented in a departmental critical incident meeting on a quarterly basis. For the purpose of reporting, a critical incident is defined as any untoward or preventable mishap which is associated 
with the administration of general or regional anaesthesia and which leads to or could have led to an undesirable patient outcome [6].

The data from these forms are added to a central computerised data base on EPI INFO 6. This database was reviewed from 1997 to 2002 for all drug related events to determine the frequency, type of error, basic cause, preventability and associated risk. Each report was evaluated individually. Using a structured process, the reports were coded by two independent reviewers (consultant anaesthetists), as preventable or unpreventable; they also coded the reports into the following basic causes:

Code 1: Drug present in an inappropriate location, e.g. present in wrong box.

Code 2: Problems related to drug labelling including wrong labelling, wrong concentration on label or presence of unlabelled drugs in the room.

Code 3: Overdosage. Drug given in dose more than indicated in literature or overdosage due to dilution error.

Code 4: Underdosage. This also included the human error if the anaesthetist forgot to give a particular drug. Underdosage because of extravasation or disconnection of apparatus was included in this category.

Code 5: Syringe swap errors, e.g. a drawn drug with proper labelling, accidentally given instead of another drawn drug.

Code 6: Drug drawn is given when not indicated, or at the wrong time, or wrong drug injected (except for syringe swap).

Code 7: Drug reaction or side-effects.

Code 8: Drug not effective after appropriate dosage.

Code 9: Miscellaneous, including delay in availability or delay in onset or recovery, or if the event did not fit in any of the above categories.

The reports were also classified into human error, equipment failure, system error or drug side-effect/complications. Human error was defined as situations where established practice was not followed and related to formulation and execution of a decision; system error was where clinical practice was badly formulated, or equipment/design error where equipment or workplace design was flawed [7]. The risk was graded as follows:

No risk, i.e. an incident without any potential risk for the patient.

Low risk, an incident which could have led to reversible damage to the patient.

Medium risk, an incident which could have led to irreversible damage to the patient.

High risk, a potentially fatal incident [8].

In cases of discrepancy between the two evaluators, the incident was rediscussed between the evaluators and a consensus reached.

\section{Results}

The total number of anaesthetics given in the main operating theatre suite during the audit period was 44 874. In all, 768 critical incidents were reported during this period, 165 of which were drug related, which constitutes $21 \%$ of critical incidents and an estimated rate of 3.6 drug related events per 1000 anaesthetics. The annual breakdown in shown in Figure 1.

Further breakdown into coded groups is given in Table 1. The highest number of incidents was related to underdosage, followed by side-effects/drug reaction and syringe swap. Both the reviewers classified $66 \%$ of the events as preventable. Classification of incidents showed that $56 \%$ were due to human error, $19 \%$ due to system error, $4 \%$ due to equipment error and $21 \%$ due to known drug side-effects. Ten percent of the incidents were labelled as high risk, $45 \%$ as medium risk and $45 \%$ as low risk. None of the incidents was labelled as no risk by the reviewers. The list of high risk cases is given in Table 2 . The administration of a long acting neuromuscular blocker instead of a narcotic was reported four times.

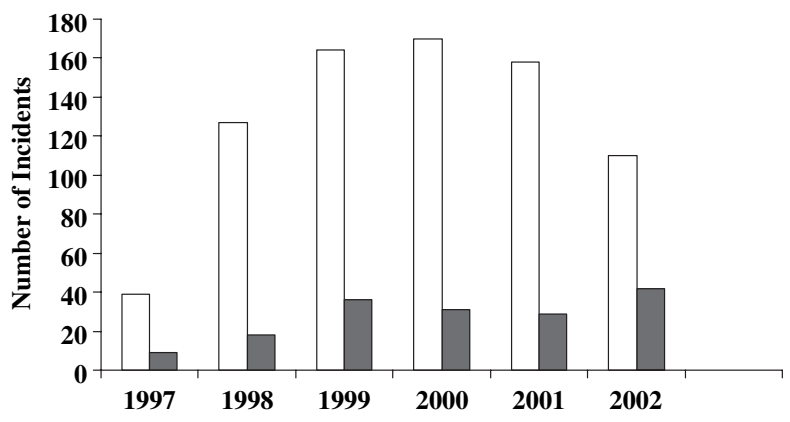

Figure 1 Number of drug related incidents in relation to total reported critical incidents. Total critical incidents per year (white bars). Drug related critical incidents (black bars).

Table 1 Categories of drug related errors (values are number of incidents).

\begin{tabular}{|c|c|c|c|c|c|c|c|}
\hline Drug error (Code) & 1997 & 1998 & 1999 & 2000 & 2001 & 2002 & Total \\
\hline $\begin{array}{l}\text { Drug in inappropriate } \\
\text { location (1) }\end{array}$ & 1 & 0 & 1 & 2 & 0 & 1 & 5 \\
\hline $\begin{array}{l}\text { Problems with } \\
\text { labelling (2) }\end{array}$ & 1 & 2 & 2 & 0 & 2 & 3 & 10 \\
\hline Overdosage (3) & 2 & 1 & 8 & 5 & 5 & 2 & 23 \\
\hline Underdosage (4) & 1 & 6 & 6 & 11 & 2 & 9 & 35 \\
\hline Syringe swap (5) & 3 & 1 & 4 & 2 & 7 & 9 & 26 \\
\hline $\begin{array}{l}\text { Wrong drug or } \\
\text { wrong timing (6) }\end{array}$ & 0 & 2 & 5 & 2 & 3 & 3 & 15 \\
\hline $\begin{array}{l}\text { Drug side-effects or } \\
\text { reaction (7) }\end{array}$ & 1 & 4 & 7 & 3 & 5 & 9 & 29 \\
\hline Drug not effective (8) & 0 & 2 & 0 & 5 & 1 & 4 & 12 \\
\hline Miscellaneous (9) & 0 & 0 & 3 & 1 & 4 & 2 & 10 \\
\hline
\end{tabular}


Table 2 Drug related events labelled as high risk.

\begin{tabular}{|c|c|}
\hline Drug group & Incidents \\
\hline \multirow[t]{5}{*}{$\begin{array}{l}\text { Neuromuscular } \\
\text { blocking agents }\end{array}$} & $\begin{array}{l}\text { Suxamethonium mixed in propofol } \\
\text { instead of lidocaine }\end{array}$ \\
\hline & $\begin{array}{l}\text { Suxamethonium instead of atropine } \\
\text { given at the time of reversal }\end{array}$ \\
\hline & $\begin{array}{l}\text { Neuromuscular blocker given } \\
\text { instead of narcotic at induction* }\end{array}$ \\
\hline & $\begin{array}{l}\text { Neuromuscular blocker given } \\
\text { instead of saline flush* }\end{array}$ \\
\hline & $\begin{array}{l}\text { Neostigmine given instead of } \\
\text { atracurium at induction }\end{array}$ \\
\hline \multirow[t]{2}{*}{ Inhalational agents } & $\begin{array}{l}\text { Halothane induced ventricular } \\
\text { tachycardia }\end{array}$ \\
\hline & Severe hypotension with sevoflurane \\
\hline \multirow[t]{2}{*}{ Local anaesthetics } & $\begin{array}{l}\text { Bupivacaine present in metaclopromide } \\
\text { box }\end{array}$ \\
\hline & $\begin{array}{l}\text { Apnoea secondary to caudal } \\
\text { injection of bupivacaine }\end{array}$ \\
\hline \multirow[t]{8}{*}{ Miscellaneous drugs } & $\begin{array}{l}\text { Potassium chloride present in } \\
\text { another drug box }\end{array}$ \\
\hline & $\begin{array}{l}\text { Severe hypotension related to } \\
\text { inadequate steroid replacement }\end{array}$ \\
\hline & $\begin{array}{l}\text { Severe hypotension following } \\
\text { injection of ampicillin }\end{array}$ \\
\hline & $\begin{array}{l}\text { Atropine underdose leading to } \\
\text { severe bradycardia at reversal }\end{array}$ \\
\hline & $\begin{array}{l}\text { Glyceryl trinitrate present } \\
\text { in midazolam box }\end{array}$ \\
\hline & $\begin{array}{l}\text { Hydralazine given instead of } \\
\text { midazolam for sedation }\end{array}$ \\
\hline & $\begin{array}{l}\text { Protamine injection causing } \\
\text { severe bronchospasm }\end{array}$ \\
\hline & $\begin{array}{l}\text { Glyceryl trinitrate given instead } \\
\text { of phenylepherine }\end{array}$ \\
\hline Fluids/blood & Haemaccel related anaphylaxis* \\
\hline products & $\begin{array}{l}\text { Fresh frozen plasma given to } \\
\text { wrong patient }\end{array}$ \\
\hline
\end{tabular}

*Event occurred more than once.

The pharmacological group of drugs involved in these incidents is listed in Table 3. The highest percentage of incidents reported were related to the neuromuscular blocking drugs $(41 \%)$, followed by a group of miscellaneous drugs $(15 \%)$ and induction agents. The miscellaneous group included neostigmine, glyceryl trinitrate, hydralazine, protamine, antibiotics, mannitol, ephedrine, insulin, metoclopramide, potassium chloride, atropine and hydrocortisone.

Although incidents related to all neuromuscular blockers were reported, the highest number (31 incidents, $45 \%)$ involved atracurium by either bolus or infusion.

The incidents reported in the first 3 years (1997-99) were compared to the incidents reported in the later period (2000-2002) to see whether any change in trends had occurred (Table 4). More errors of underdosage and syringe swaps were reported during the later period.
Table 3 Pharmacological group of drugs involved in drug related critical incidents (values are number of incidents).

\begin{tabular}{lc}
\hline $\begin{array}{l}\text { Pharmacological } \\
\text { drug group }\end{array}$ & $\boldsymbol{n}=\mathbf{1 6 5}$ \\
\hline Sedatives & 3 \\
Induction agent & 17 \\
Narcotics & 13 \\
Neuromuscular blockers & 68 \\
Local anaesthetics & 13 \\
Inhalational agents & 14 \\
Intravenous fluids & 4 \\
Miscellaneous & 25 \\
More than two drugs & 6 \\
Drug not documented & 2 \\
\hline
\end{tabular}

Table 4 Drug related critical incidents: comparison of two periods (values are number of incidents).

\begin{tabular}{lcc}
\hline Drug error & 1997-99 & 2000-2002 \\
\hline Drug in inappropriate location & 2 & 3 \\
Problems with labelling & 5 & 5 \\
Overdosage of drug & 11 & 12 \\
Underdosage of drug & 13 & 22 \\
Syringe swap & 8 & 18 \\
Wrong drug given or wrong timing & 7 & 8 \\
Known drug side-effects or reaction & 12 & 17 \\
Drug not effective & 2 & 10 \\
Miscellaneous & 3 & 7 \\
\hline
\end{tabular}

\section{Discussion}

Critical incident analysis is a method of gathering information that allows the identification of mechanisms and contributing factors, and may be helpful in the formulation of strategies to prevent recurrence. This simple quality improvement and risk reduction measure can also help improve the standard of anaesthetic care in developing countries, where the low running cost is particularly important [9]. Drug related incidents have been reported in various studies $[10,11]$ and have recently been the topic of a systematic review [12]. Drug related incidents form $7-32 \%$ of reported errors $[4,13,14]$. Human error accounted for $51 \%$ of our drug related incidents. This is in accordance with findings in other studies. Short et al. reported that $80 \%$ of critical incidents associated with anaesthesia in general are caused by human error [14]. The same appears to be true for the drug related incidences, where the majority are due to human error.

Underdosage of drugs was the most common incident reported. Several reasons were cited: anaesthesia machine fault, faulty vaporiser, flowmeter not turned on at 
induction, extravasation of drugs due to faulty intravenous cannulation technique, disconnection of intravenous line which went unnoticed, malfunction of syringe pumps due to human or equipment error, and the drug being ineffective even when given in an appropriate dose.

The other errors reported were side-effects or drug reactions, followed by syringe swap. The most common drugs involved in syringe swap were neuromuscular blocking drugs. In 17 of 26 incidents, either the neuromuscular blocker was inadvertently given instead of another drug or another drug was given instead. The reason could be the use of 5-ml syringes for both nondepolarising muscle relaxants and narcotic dilutions at our institution. This practice is now being altered. In 1984, Cooper et al. [15] reported on commonly described critical incidents; syringe swap was one of the most frequently cited.

Seventy-seven percent of our errors were classified as preventable and $23 \%$ as nonpreventable. There was a difference between the drug incidents for the first 3 years (1997-99) and those for the subsequent 3 years (20002002). In the former period, 63 incidents were reported, compared to 102 in the later. The difference was mainly seen in errors of underdosage and syringe swap, where the incidences increased in the later period. Awareness of residents and faculty in reporting incidents, or the constant change-over of residents and anaesthesia technicians could have led to more errors occurring. The trend in the department has also changed; more syringe pump infusions, especially for muscle relaxants, are now used.

A suggested approach in the management of errors is to find out what is occurring, collate the information, categorise problems, contributing factors and errors, particularly identifying the latent errors, and then to develop preventable strategies. After these strategies are in place it is necessary to assess their effectiveness [8]. It has also been suggested that even in the case of heterogeneous results, targeting high priority areas could decrease the overall frequency of events [16]. Quality Assurance Issues (QAI) meetings in our department were started in the year 2000, at which selected errors that are picked up from the critical incident list are discussed and appropriate changes made, or guidelines formulated. Following the above approach we attempted to determine the latent errors in this audit. The importance of the contribution of latent errors to the occurrence of major disaster is well known [17]. Latent errors are defined as problems that management can address [2]. Incidents caused by latent errors do not recur after their removal. The latent errors that have been identified in this audit relate to labelling of drugs in the operating theatre, use of ward cannula for intravenous induction, presence of ampoules at the wrong site, missing information of timing of drug preparation on the syringe label, and communication between the anaesthetic technician and anaesthetist. Some of these have been addressed at our QAI meetings and others will be taken up soon.

The main lessons learnt from these errors were that:

- neuromuscular blockers were the largest pharmacological group involved in drug errors;

- preventive strategies for continuing technician and resident education needed to be put in place as both these groups had a certain yearly attrition rate.

In errors relating to muscle relaxants, the majority of incidents involved atracurium. A possible latent error involving a storage problem was thought to be responsible in a number of cases and was looked at in detail. The drug is imported by pharmaceutical companies and sometimes involves procedures beyond institutional control, e.g. storage at custom or company warehouses. If the drug is not stored properly, its efficacy can be affected, especially in tropical countries. We have tried to improve guidelines regarding storage in our own pharmacy and department. It is also now mandatory to write the time of drawing the drug.

The labelling and presence of drug in inappropriate locations also accounted for 15 errors. Earlier studies have also highlighted drug related critical incident, the majority being attributable to failing to read or misreading the label, mislabelling, confusion with labels, or drugs being present in the wrong boxes [10, 18]. Labelling of syringes is compulsory in our department but previously the labels were not colour coded and a simple piece of sticky tape was used. We have recently introduced the international colour coded drug labels in our department. This will cost the patient an extra two rupees (US\$ 0.004) per injection, but this was considered necessary for risk management. It will be interesting to study whether drug swap errors will be reduced after the introduction of this system. The other changes introduced were removal of dangerous drugs such as potassium chloride from the operating theatre and not storing ampoules of similar size and appearance next to each other. Our pharmacy has also introduced the placement of distinct coloured labels on the ampoules of dangerous drugs. Drug related errors are now also being reported to our Pharmacy and Therapeutics Committee on a regular basis so that some institutional strategies could be put in place.

One of the problems with this method of critical incidents reporting is that some under-reporting is inevitable and the absolute frequency of events is not known. However, awareness of the problem does increase with recurrent reporting [19]. Studies determining absolute incidences are expensive [8]. We also plan to carry out selective audits in future to detect problems not covered well by incident monitoring. 
In conclusion, this audit has highlighted some areas in drug usage in our department which need to be addressed on a priority basis.

\section{Acknowledgements}

We would like to thank all the members of the Anaesthesia Department who filled in the critical incident forms.

\section{References}

1 Cooper JB, Newbower RS, Long CD, et al. Preventable anaesthesia mishaps: a study of human factors. Anaesthesiology 1978; 49: 399-406.

2 Short TG, O'Regan A, Jayasuriya JP, et al. Improvements in anaesthetic care resulting from a critical incident reporting programme. Anaesthesia 1996; 51: 615-21.

3 Runciman WB. Report from the Australian Patient Safety Foundation. Anaesthesia and Intensive Care 1988; 16: 114-6.

4 Web RK, Curie M, Morgan CA, et al. The Australian Incident Monitoring Study: an analysis of 2000 incident reports. Anaesthesia and Intensive Care 1993; 21: 520-8.

5 Kanjanarat P, Winterstein AG, Johns TE, et al. Nature of preventable adverse drug events in hospitals: a literature review. American Journal of Health-System Pharmacy 2003; 60: 1750-9.

6 Curie M. A prospective survey of anaesthetic critical events in a teaching hospital. Anaesthesia and Intensive Care 1989; 17: 403-11.

7 Runciman WB, Sellen A, Webb RK, et al. Incidents and accidents in anaesthetic practice. Anaesthesia and Intensive Care 1993; 21: 506-19.

8 Chopra V, Bovill JG, Spierdigk J, et al. Reported significant observations during anaesthesia: a prospective analysis over an 18-month period. British Journal of Anaesthesia 1992; 68: 13-7.

9 Khan FA, Hoda MQ. A prospective survey of intra-operative critical incidents in a teaching hospital in a developing country. Anaesthesia 2001; 56: 171-82.

10 Webster CS, Merry AF, Larsson L, et al. The frequency and nature of drug administration error during anaesthesia. Anaesthesia and Intensive Care 2001; 29: 494-500.

11 Orser BA, Chen RJ, Yee DA. Medication errors in anaesthetic practice. a survey of 687 practitioners. Canadian Journal of Anaesthesia 2001; 48: 139-46.

12 Jensen LS, Merry AF, Webster CS, et al. Evidence-based strategies for preventing drug administration errors during anaesthesia. Anaesthesia 2004; 59: 493-504.

13 Hugh James R. 1000 anaesthetic incidents: experience to date. Anaesthesia 2003; 58: 856-63.

14 Short TG, O’Regan A, Lew J, et al. Critical incident reporting in an anaesthetic department quality assurance programme. Anaesthesia 1992; 47: 3-7.

15 Cooper JB, Newbower RS, Kitz RJ. An analysis of major errors and equipment failures in anaesthesia management: considerations for prevention and detection. Anaesthesiology 1984; 60: 34-42.

16 Vincent C, Neale G, Woloshynowych M. Adverse events in British Hospitals: preliminary retrospective record review. British Medical Journal 2001; 322: 517-9.

17 Reason J. Human Error. Cambridge: Cambridge University Press, 1990.

18 Fasting S, Grisvold SE. Adverse drug errors in anaesthesia and the impact of coloured syringe labels. Canadian Journal of Anaesthesia 2000; 47: 1060-7.

19 Kumar V, Barcellos WA, Mehta MP, et al. An analysis of critical incidents in a teaching department for quality assurance. A survey of mishaps during anaesthesia. Anaesthesia 1988; 43: 879-83. 